\title{
PRÁTICA DOCENTE: A UTILIZAÇÃO DA AFETIVIDADE NA EDUCAÇÃO INFANTIL
}

\author{
PRÁCTICA DOCENTE: LA UTILIZACIÓN DE LA AFETIVIDAD EN LA \\ EDUCACIÓN INFANTIL
}

TEACHING PRACTICE: THE USE OF AFETIVITY IN CHILD EDUCATION

\author{
Fábio Tadeu REINA ${ }^{1}$ \\ Luiz Henrique MAURICIO ${ }^{2}$ \\ Lígia Moreira CESAR ${ }^{3}$
}

RESUMO: O ambiente educacional há algum tempo vem sofrendo inúmeras transformações, principalmente no que tange à temática das práticas pedagógicas docentes. Neste trabalho de cunho qualitativo será abordado a afetividade como um dos principais aspectos que facilitam a relação ensino-aprendizagem de crianças de 0 a 5 anos de idade. $\mathrm{O}$ componente afetivo no ambiente educativo funciona como um agente motivador que impulsiona à participação ativa no processo de aprendizagem e consequentemente influencia o desenvolvimento. Diante do levantamento feito através de conteúdo bibliográfico fica evidente que a construção de um ambiente afetivo para os alunos é muito importante para despertar o interesse e facilitar na construção do saber.

PALAVRAS-CHAVE: Afetividade. Educação infantil. Prática pedagógica.

RESUMEN: El ambiente educativo hace algún tiempo viene sufriendo innumerables transformaciones, principalmente en lo que se refiere a la temática de las prácticas pedagógicas docentes. En este trabajo de cuño cualitativo se abordará la afectividad como uno de los principales aspectos que facilitan la relación enseñanza-aprendizaje de niños de 0 a 5 años de edad. El componente afectivo en el ambiente educativo funciona como un agente motivador que impulsa la participación activa en el proceso de aprendizaje y consecuentemente influye en el desarrollo. Ante el levantamiento hecho a través de contenido bibliográfico queda evidente que la construcción de un ambiente afectivo para los alumnos es muy importante para despertar el interés y facilitar en la construcción del saber.

PALABRAS CLAVE: Afectividad. Educación infantil. Práctica pedagógica.

${ }^{1}$ Universidade de Araraquara (UNIARA), Araraquara - SP - Brasil. Vice Coordenador do Programa Mestrado Profissional em Educação: Processos de Ensino, Gestão e Inovação. ORCID: <http://orcid.org/0000-0002-2591-2378>. E-mail: ftreina@ hotmail.com

${ }^{2}$ Universidade de Araraquara (UNIARA), Araraquara - SP - Brasil. Aluno do Mestrado Profissional em Educação: Processos de Ensino, Gestão e Inovação. ORCID: <https://orcid.org/0000-0002-5447-5111>. E-mail: lhenrique_e@hotmail.com

${ }^{3}$ Universidade de Araraquara (UNIARA), Araraquara - SP - Brasil. Aluna do Mestrado Profissional em Educação: Processos de Ensino, Gestão e Inovação. E-mail: ligiamoreiracesar@gmail.com 
ABSTRACT: The educational environment for some time has undergone numerous transformations, mainly in what concerns the theme of teaching pedagogical practices. In this qualitative study, affectivity will be approached as one of the main aspects that facilitate the teaching-learning relationship of children from 0 to 5 years of age. The affective component in the educational environment functions as a motivating agent that promotes active participation in the learning process and consequently influences development. Faced with the survey made through bibliographic content it is evident that the construction of an affective environment for the student is very important to arouse interest and facilitate the construction of knowledge.

KEYWORDS: Affectivity. Child education. Pedagogical practice.

\section{Introdução}

A proposta deste estudo surgiu através da afinidade e interesse na educação infantil por entender que este nível de escolarização é importante e também por compreender que esta formação primária é relevante para que o aluno se desenvolva com qualidade e plenitude de suas capacidades.

O âmbito da educação infantil vem sofrendo inúmeros e intensos processos de reorganização sobre como educar as crianças em espaços interescolar e extraescolar. A primeira abordagem desta temática se deu a partir da mudança legislativa no ambiente educativo que garante o direito a todos de terem atendimento nas creches e pré-escolas. Isso foi possível através da Lei de Diretrizes e Bases da Educação Nacional (Lei $\mathrm{n}^{\circ}$ 9.394/96), que teve como objetivo o reconhecimento da educação infantil como um dever e obrigação do Estado, aliado ao processo educacional (BRASIL, 1996).

Após este reconhecimento legal da educação infantil como dever e obrigação do Estado associado ao processo educacional, iniciou-se a elaboração de documentos que servissem como respaldos pedagógicos, tendo em vista que o trabalho desenvolvido dentro das escolas de Educação Infantil não ficasse apenas voltado para cuidar, mas também para ampliar o conhecimento cientifico a respeito da educação de crianças de 0 a 5 anos de idade. Para tanto, faz-se necessário o respeito acerca da idade desse aluno atendido dentro dessa primeira etapa da educação básica e que também fizesse uma ligação aos campos contextuais, procedimentais e atitudinais.

Para nortear o presente estudo há documentos legais, tais como as Diretrizes Nacionais Curriculares (DCN) voltadas à educação infantil, a qual está respaldada nas Diretrizes Nacionais da Educação Básica do Conselho Nacional de Educação. As DCNs apontam propostas de organização do trabalho a ser realizado na educação infantil, 
elaborando assim um currículo pautado em planejamento, ação e avaliação. Outro aspecto importante ligado a este documento é que essas diretrizes englobam também as leis de cada Município, Estado e do Sistema Público.

Gostaríamos de chamar atenção, então, para algumas das particularidades desse nível escolar, embora o cunho científico deva estar presente para um desenvolvimento integral do aluno atendido, como é bem definido nas DCNs. As práticas pedagógicas também devem ser elaboradas e realizadas na Educação Infantil tendo como instrumento de trabalho jogos e brincadeiras que proporcionem a construção de conhecimento próprio e do mundo que a cerca, de modo sensitivo, expressivo e corporal, e que obtenham respeito por seus desejos e pelo próximo. Ou seja, que propicie às crianças um leque de experiências para que ampliem a visão que já possuem e construam uma visão de mundo mais humano.

Foi utilizado neste trabalho a ideia de uma visão mais humana segundo a perspectiva de Vigotski (2007), que defende que quanto mais o indivíduo se aproxima do conhecimento, mais este se aproxima da humanidade. Para esse autor, a criança desde seus primeiros dias de vida começa a apropriar-se de significados sociais do ambiente em que está inserida, que o permite pertencer a uma determinada cultura. Conforme a criança se desenvolve, a construção primária de significados amadurece fazendo com que ela posteriormente adote valores, comunique-se, crie saberes, crie comportamentos e novos modos de agir.

Essa interação do adulto com o bebê, com a criança, com o indivíduo em formação, entendemos que a prática do profissional escolar deve ser realizada de modo responsável e coeso para favorecer a formação do aluno.

\section{Práticas pedagógicas na educação infantil}

Segundo Souza (2004), por prática pedagógica se entende as relações professoraluno; aspectos metodológicos; avaliação; epistemologia do que é educação e do que é escola. Segundo as pesquisadoras Martins, Morais e Santos (2014) a práxis-pedagógica é a relação entre teoria e prática, ambas não devem se separar durante uma atividade e muito menos serem trabalhadas de forma desconexa do ambiente. Essa prática exige uma constante reflexão do docente para poder intervir na sociedade e no contexto educacional. 
Sobre a prática docente, Sacristán (2007) exclama que todos temos internamente vivências práticas sobre a vida e de como as coisas funcionam, principalmente àquelas correlacionadas ao ensino, de como o conhecimento é transmitido e recebido. Portanto, fica evidente a contribuição que a prática docente tem na formação dos alunos.

Para contextualizar as práticas pedagógicas hoje ou em qualquer que seja a circunstância, é preciso primeiro analisar algumas características que acabam fazendo parte desta terminologia e que muitas vezes não são verificadas. É preciso, a priori, analisar os contextos de formação econômica em que se está inserido, também as relações culturais e sociais para começar a compreender as práticas pedagógicas. Tal prática, segundo o autor, também pode funcionar como uma via de mão dupla, possibilitando que sua utilização cause uma transformação positiva no discente ou apenas funcione como um reservatório de conhecimento, onde o professor apenas 'despeja' o conteúdo e não traz para o contexto uma reflexão do que se está trabalhando em sala de aula. No ambiente escolar o uso da reflexão, da gestão democrática, dos processos de participação e de pesquisa acabam contribuindo para reestruturar as práticas pedagógicas em sala de aula. Quando o docente faz uso destas caraterísticas para planejar suas aulas, essas peculiaridades o ajudam a superar a alienação de seus alunos e consequentemente formar uma sociedade menos controlada (SOUZA, 2004).

No ensino infantil, devemos iniciar e organizar uma prática partindo do pressuposto que o docente deve agir como um mediador das relações e experiências que cercam as crianças, que possibilitarão um desenvolvimento gradativo para trabalhar aspectos como: tomada de decisão, elaboração de regras, justiça, cooperação, solidariedade, dialogação, respeito a si próprio e ao próximo (NEIRA, 2003).

Ainda sobre as práticas docentes, os autores Oliveira e Formosinho (2004-2007) dão destaque para necessidade desta prática na educação infantil ter uma proposta de ação participativa. A relação entre o professor e a aluno é importante para ampliação dos contextos culturais em que a criança está inserida. Vale ressaltar que esta transformação se faz através de um professor mediador que utiliza alguns recursos em suas aulas que consequentemente acabam favorecendo a construção dos saberes das crianças, sempre os vinculando com a realidade cultural, material e da compreensão já existentes do mundo que as cercam. Por isso, a viabilização de oportunidades e de experiências são consideradas também um eixo central na prática docente por despertarem o interesse dos alunos e contribuírem para sua formação. 
Entende-se que o profissional de Educação Infantil, e utilizamos esse termo, pois são vários os profissionais que lidam com as crianças, tais como agentes educacionais, berçaristas, recreacionistas, professores, devem ter a sua prática consciente, planejada e pensada em cima de uma mediação afetiva. A ação desse profissional pode contribuir para que o aluno estabeleça relações com o mundo. Essas relações não serão só no âmbito do tratamento de si e de tratar ao outro, no entanto, a afetividade também será primordial para aprendizagem e estimulação da criança.

\section{A utilização da afetividade na educação infantil}

De modo mais amplo o afeto pode ser entendido como um aglomerado de emoções, sensações e sentimentos que acompanham os seres humanos, ele é capaz de promover mudanças no próximo através de sentimentos estimulados por meio da interação e troca de experiências (DE SOUZA VIEIRA, 2004).

Para Wallon (2007), a afetividade deve ser condicionada para a prática pedagógica para que a criança seja trazida para a situação real de aprendizagem, em que serão criados meios de reter a atenção deste aluno, por conseguinte, faz com que o discente adquira um certo carinho por certa situação ou pessoa. Quando o docente consegue criar um ambiente afetivo para o aluno, este começa a realmente se apropriar de todo conhecimento que está sendo ofertado. Ainda sobre esta temática, o autor fala que este universo afetivo ganha vida através das interações cognitivas e motoras, que tem início desde o nascimento, e a interação entre as duas vertentes causa no aluno o afeto por tal atividade ou pessoa.

O termo "emoções" servirá para elucidar o uso da afetividade na vida das crianças. As dimensões afetivas estão presentes desde o nascimento e prevalecem por grande parte de sua evolução mental durante sua trajetória de vida. É importante destacar que esta construção não se dá através do primeiro contato com o mundo e suas propriedades, mas sim pela evolução da criança até a fase adulta. Portanto, essa evolução surge a partir da relação com o meio social e orgânico.

Os autores Nascimento; Oliveira; Fátima (2017) apontam em seus estudos a importância de trabalhar a questão afetiva no ambiente escolar, principalmente no que tange à prática pedagógica docente. $\mathrm{O}$ ambiente escolar passa a ser um dos primeiros ambientes socializadores que a criança frequenta após sair do ambiente familiar e é a partir daí que ela começa a ampliar suas experiências. Quando os professores, no 
ambiente escolar, trabalham fazendo o uso da afetividade no processo de formação de seus alunos, isso acaba trazendo benefícios, principalmente no que se refere à educação infantil. Para que esta ação comece a dar frutos é necessário trabalhar nas aulas com atividades que envolvam o brincar, sempre na perspectiva lúdica para estimular a criança e propiciar novas experiências e saberes. Esse novo contato simplifica a transmissão e aquisição de conhecimento, tornando esse processo prazeroso e dá subsídio para as próximas fases em que a criança será inserida.

Segundo Amorim e Navarro (2012), a educação infantil é formada por três agentes além das crianças, representados pela família, escola e corpo docente. Essas participações são centrais para que a criança tenha subsídio para progredir em sua vida, cada um tem uma função que fornece à criança parâmetros para conhecer a si próprio, ao mundo e se relacionar com ele. No ambiente escolar, o uso da afetividade é imprescindível para que a criança crie sua identidade e adquira os saberes com os recursos necessários para sua trajetória de vida. $\mathrm{O}$ ambiente educacional não deve ir contra o princípio de promover a afetividade nas relações escolares, mas deve construir um cenário socioafetivo para que seja ampliado e solidificado, tendo como resultado uma formação mais íntegra.

\section{Considerações finais}

Diante do levantamento da literatura e das informações encontradas, fica muito claro que o uso da afetividade se torna componente facilitador e motivador da aprendizagem, o que é algo muito importante para o ambiente escolar e para o desenvolvimento das crianças, além de contribuir para que o aluno construa sua identidade e se expresse diante de algumas situações que porventura possam contribuir para formar uma sociedade mais consciente.

\section{REFERÊNCIAS}

BRASIL. Lei de Diretrizes e Bases da Educação Nacional, LEI No 9.394, DE 20 DE DEZEMBRO DE 1996. - Art. 26 § 30. Disponível em:

<http://www.planalto.gov.br/ccivil_03/leis/L9394.htm>. Acesso em: 20 dez. 1996.

BRASIL, MEC; CNE, CEB. Diretrizes Curriculares Nacionais para a educação infantil. Resolução CEB-CNE, n. 1, 2010.

DE SOUZA VIEIRA, R. M. Afetividade e aprendizagem. 2004. 
DO NASCIMENTO, V. H.; DE OLIVEIRA, M. A. M.; DE FÁTIMA, O. M. Afetividade na educação infantil. Revista Saberes Docentes, v. 2, n. 3, 2017.

GIMENO AS CRISTÁN, J. O que são os conteúdos do ensino? In: SACRISTÁN, J. Gimeno. Compreender e transformar o ensino. 4. ed. Porto Alegre: Artmed, 2007. Cap. 6, p. 119-147.

MARTINS, N.; MORAES, D. A. F. de.; SANTOS, A. R. de J. Concepção docente: a prática pedagógica em questão. 2014.

MEIER, M.; GARCIA, S. Mediação da aprendizagem: contribuições de Feurstein e Vygostky. Curitiba: Edição do Autor, 2007.

NEIRA, M. G. Educação física: desenvolvendo competências. São Paulo: Phorte, p. 183-198, 2003.

OLIVEIRA-FORMOSINHO, J. A participação guiada: coração da pedagogia na Infância? Revista Portuguesa de Pedagogia, Coimbra, n.38, v. 1-3, p. 145-158, 2004.

OLIVEIRA-FORMOSINHO, J. Pedagogia(s) da Infância: reconstruindo uma práxis de participação. In: OLIVEIRA-FORMOSINHO, J.; KISHIMOTO, T. M.; PINAZZA, M. A. (Orgs). Pedagogia da infância: dialogando com o passado, construindo o futuro. Porto Alegre: Artmed, 2007.

VIGOTSKI, L. S. O instrumento e o símbolo no desenvolvimento da criança. In: VIGOTSKI, L. S. A formação social da mente. 7 ed. São Paulo: Livraria Martins Fontes Editora Ltda, 2007. Cap. 3. p. 19-20.

WALLON, H. A Afetividade. In: WALLON, H. A evolução psicológica da criança. São Paulo: Livraria Martins Fontes Editora Ltda, 2007. Cap. 9. p. 118-126. Claudia Berliner.

\section{Como citar este artigo}

REINA, Fábio Tadeu.; MAURICIO, Luiz Henrique.; CESAR, Lígia Moreira. Prática docente: a utilização da afetividade na educação infantil. Temas em Educação e Saúde, Araraquara, v.14, n.1, p. 55-61, jan./jun., 2018. E-ISSN: 2526-3471. DOI: 10.26673/rtes.v14.n1.2018.10728.

Submetido em: $30 / 11 / 2017$

Aprovado em: 04/05/2018 